\title{
Tradisi Baru Perpustakaan dalam Perannya sebagai Institusi Pengetahuan
}

\author{
Ifonila Yenianti \\ IAIN Salatiga
}

\begin{abstract}
Library is not only a place to display books, but there are many important values within. The Library paradigm of book oriented has shifted into user oriented. It means that library becomes a centre of information. On the top of that, library is also transforms into a knowledge institution to serve, illuminate, and make knowledge as a culture. In this technological era, this article presents interesting phenomena in The Libraries of State Institute for Islamic Studies (PTKIN) under The Ministry of Religious Affairs Indonesia about the emergence and the development of new traditions including Online Research Skills (ORS) and Writing Skills (WS)
\end{abstract}

Keywords : New Traditions, Online Research Skills, Writing Skills.

\section{Pendahuluan}

Perpustakaan yang menjadi sentralnya pengetahuan adalah sebuah institusi yang mendedikasikan diri sebagai pengelola informasi, baik yang terkait dengan perpustakaan itu sendiri maupun dengan bidang lain yang menjadi salah satu faktor terbentuknya karakter dan pengetahuan anak bangsa.Betapa tidak, perpustakaan dengan berbagai informasi yang disediakannya, memberikan peluang-peluang bagi pemustaka untuk mengeksplorasi informasi-informasi yang dikelolanya. Bahkan informasi yang diperoleh dari perpustakaan boleh dimodivikasi sehingga menjadi 
pengetehauan baru. Namun sayang, perpustakaan dalam sudut pandang masyarakat Indonesia secara umum masih dianggap hanya sekedar institusi pengelola buku semata. Mereka masih menyimpan buruknya memori dan pengalaman lama dalam dirinya mengenai jati diri perpustakaan.

Padahal beberapa dasawarsa sebelumnya Ranganathan sudah memberikan statement yang dikenal dengan lima hukum perpustakaan. Nama lengkapnya adalah Shiyali Ramamrita Ranganathan (1892-1972), Dia disebut sebagai bapaknya ilmu perpustakaan di India. Ranganathan mengembangkan konsep ideal bagi pelayanan perpustakaan. Konsep itu dikenal dengan lima hukum ilmu perpustakaan yang hingga kini masih dijadikan sebagai literatur rujukan. Lima hukum ilmu perpustakaan itu dijadikan pula sebagai landasan filosofi perpustakaan, yaitu:

1. Books are for use.

2. Every reader his or her book.

3. Every book its reader.

4. Save the time of the reader.

5. The Library is a growing organism. ${ }^{1}$

Pemikiran manusia pun berubah seiring perkembangan jaman. Pada saat komputer menjadi icon perkembangan teknologi, dan pada saat internet menjadi pahlawannya berjejaring pada masa modern seperti sekarang ini, Gorman muncul sebagai pemikir baru yang mendialogkan kondisi perpustakaan masa lalu dengan perpustakaan yang sedang dalam proses pengembangan yang berbasis teknologi informasi. Gorman mengemukakan pendapatnya mengenai perpustakaan dalam lima hal, yang kemudian dikenal dengan Gorman's laws. Dia mengitepretasikan kembali hukumnya Ranganathan itu ke dalam konteks kekinian. Gorman berpendapat bahwa:

1. Libraries serve humanity

2. Respect all forms by which knowledge is communicated.

3. Use technology intelligently to enhance service

${ }^{1}$ Alireza Noruzi, “Application of Ranganathan's Laws to the Web," Webology 1, no. 2 (2004): 2, http://eprints.rclis.org/handle/10760/7252. 
4. Protect free access to knowledge; and

5. Honor the past and create the future ${ }^{2}$

Gorman melihat sisi dinamisnya perpustakaan yang didialogkan dengan perkembangan masa kini secara bijaksana. Unsur budaya yang mewarnai perpustakaan sebagai unit pelayanan disandingkan dengan peran teknologi yang dapat saling mendukung untuk mengelola dokumen masa lalu dan menciptakan masa depan. Pertanyaanya adalah budaya apakah yang dimaksud?

Pada konteks ini, budaya tidak lepas dari proses berfikir yang mengalir dalam rutinitas kerja perpustakaan. Maka dari proses berfikir itu, muncul pemikiran tentang peran perpustakaan yang dekat dengan perkembangan teknologi dan informasi.

\section{Peran perpustakaan}

Informasi pada era sekarang seolah menjadi bagian tak terpisahkan dengan kemajuan selain kemajuan yang disimbolkan dengan kehadiran teknologi. Bisa dikatakan disini bahwa jika teknologi adalah container-nya, atau dengan kata lain teknologi sebagai alat, maka informasi adalah content nya. Perpustakaan adalah institusi yang bisa mengelola informasi itu dengan bentuk data yang terekam. Informasi terekam itu bisa dianggap sebagai sejarah masa lalu yang dapat dijadikan rujukan untuk menciptakan masa depan.

Floridi berpendapat jika sejarah itu sesungguhnya adalah informasi masa lalu yang terekam. Karena sejarah orang menjadi bijaksana, karena sejarah orang akan bisa berfikir cerdas. Perubahan berfikir ini disebabkan keberhasilan memaknai peristiwa yang sudah terjadi. Oleh sebab itu dapat dikatakan bahwa sejarah merupakan bagian dari budaya. No records no history, so history is actually synonimous with the information age, since prehistory is that age in human development that precedes availability of recording systems. ${ }^{3}$

${ }^{2}$ G.E Gorman and Peter Clayton, Qualitative Research For The Information Proffessional: A Practical Handbook, 2nd ed. (London: Facet Publishing, 2005).

${ }^{3}$ Luciano Floridi, Information: A Very Short Introduction (Oxford, 1995), 3. 
Menurut Gordon, setidaknya ada lima hal yang menciptakan suatu landasan praktis kepustakawanan, dan dianggap sebagai peran pokok perpustakaan terkait dengan informasi, yaitu:

1. Collect Information, Perpustakaan mengumpulkan koleksi untuk yang berorientasi pada pemenuhan kebutuhan pemustaka terhadap informasi.

2. Acquire Information, Perpustakaan melakukan proses evaluasi, menyeleksi dan melakukan pengadaan sesuai dengan kebutuhan pemustaka.

3. Organize Information, Perpustakaan mengorganisasikan informasi termasuk di dalamnya melakukan klasifikasi, pengatalogan, dan juga mengatur sistem temu kembalinya.

4. Retrieve Information, perpustakaan menjadi fasilitator dalam hal menemukan kembali informasi.

5. Disseminate Information, Perpustakaan juga menjadi institusi pertama yang memiliki ikatan emosional dengan perbukuan. ${ }^{4}$

Kelima peran ini adalah tugas pokok perpustakaan dalam mengelola informasi. Dan inilah sebenarnya bentuk budaya perpustakaan yang melekat dan selalu dikembangkan. Perkembangan itu bisa dicontohkan pada The academic library in the University of Technology yang memainkan peran dalam dunia akademik dalam hal penciptaan dan penyebaran informasi ilmiah. Sejak diketahuai bahwa publikasi ilmiah di Afrika dalam posisi tertinggal, Para akademisi Afrika merasa malu dan terpacu untuk melakukan memperbanyak publikasi ilmiah di jurnal-jurnal lokal. Sikap mereka ini mengakibatkan perubahan pada penerbitan lokal dan meningkatkan nilai promosi lembaga induknya ketika publikasi jurnal di Afrika diakses secara global sebagai sumber penelitian yang berkualitas (kredibel). ${ }^{5}$ Contoh perkembangan peran ini mengispirasi penulis untuk melihat budaya yang kini sedang berkembang pada lingkup Perpustakaan Peguruan Tinggi Islam Negeri (PTKIN) Indonesia. 2004), 19.

${ }^{4}$ Rachel Singer Gordon, The Accidental Library Manager (Medford, N.J: Information Today,

${ }^{5}$ Elisha R.T. Chiware, "Positioning the Technological University Library in Higher Education and Human Resources Development in Africa," Library Management 31, no. 6 (July 27, 2010): 397, doi:10.1108/01435121011066153. 


\section{Peran Perpustakaan sebagai Pelestari Budaya}

Perpustakaan memiliki fungsi sebagai pelestari budaya, artinya perpustakaan adalah tempat dikelolanya berbagai ilmu pengetahuan, sedangkan pengetahuan itu adalah hasil dari budaya berfikir, budaya berlaku ilmiah dan budaya meracik pengalaman. Budaya dalam makalah ini meluas pada peradaban. Sementara peradaban itu sendiri adalah perkembangan pemikiran manusia yang disimbolkan pada artefak dan dokumen bernilai sejarah.Adalah benar jika dikatakan perpustakaan melestarikan budaya, karena perpustakaan memang tempatnya informasi hasil dari pemikiran manusia dalam bentuk informasi yang terekam.

Pergeseran dari dunia analog ke dunia digital sangat memerlukan usaha perpustakaan dalam beradaptasi dan memerlukan keterbukaan dalam menerima setiap perubahan. Tidak terkecuali dengan munculnya internet yang menjadi icon perkembangan di masa digital sekarang ini.

Kehadiran internet telah memunculkan optimisme yang sangat tinggi terhadap kemudahan dan kecepatan akses terhadap informasi. Sementara euforia terahadap kekuatan internat juga memunculkan pesimisme yang tinggi pula terhadap eksistensi perpustakaan karena keterbatasan pengelola perpustakaan untuk mengikuti perkembangan teknologi informasi itu.

Sejak munculnya internet budaya berfikir pun berubah. Pengguna internet di dunia mencapai 3.175 Milyar jiwa, dan Indonesia menempati urutan keenam terbesar di dunia dengan jumlah diperkirakan mencapai 88,1 juta pengakses internet selama tahun 2014. Dari jumlah tersebut sebagian besari memiliki dan menggunakan aplikasi jejaring sosial sebesar 87,4\%, sisanya masih menggunakan cara yang konvensional. ${ }^{6}$

Data statistik ini menunjukkan peminatan terhadap internet dengan berbagai macam jenis kebutuhan penggunanya. Artinya tanpa disadari kebutuhan terhadap informasi pun meningkat, terlepas dari substansi informasi yang diaksesnya.

\footnotetext{
${ }^{6}$ Nuning Kurniasih, "Kualifikasi Pustakawan Di Era Digital," in Prosiding Semiloka Kepustakawanan Indonesia 2015 (Jakarta: FPPTI, 2015), 439.
} 


\section{Budaya dan Pemikiran}

Budaya yang berkembang di masyarakat sesunguhnya sejalan dengan pola pikir masyarakat itu sendiri. Dan hasilnya juga dapat berupa nilai, sikap dan juga dalam bentuk artifak. Ketiganya ini ada di perpustakaan. Perpustakaan mengelola pengetahuan, nilai-nilai budaya, pelayanan prima sebagai representasi dari sikap dan buku sebagai wakil dari sebuah artifak. Terdapat dua peran penting perpsutakaan dalam pelestarian budaya, yaitu:

1. Revitalisasi Nilai-nilai budaya Hal terpenting dalam upaya pelestarian khasanah budaya bangsa adalah pelestarian nilai-nilai luhur budaya yang menjadi petunjuk sikap dan tingkah laku dalam kehidupan sosial budaya. Pelestarian budaya yang hanya ditujukan pada perawatan fisik benda-benda peninggalan purbakala tidak akan memberikan pengaruh besar pada upaya bangsa Indonesia dalam mencapai kemajuan. Bangsa Indonesia membutuhkan identitas atau jati diri sebagai sebuah bangsa dan hal itu hanya dapat dilakukan dengan menumbuhkan kesadaran akan pemahaman terhadap kenyataan sejarah dan budaya.

2. Menumbuhkan Kembali Tradisi yang Terputus Penerjemahan dan penyaduran naskah-naskah kuno dari bahasa aslinya ke dalam bahasa-bahasa yang digunakan oleh masyarakat modern telah banyak dilakukan oleh para ahli dari dalam maupun luar negeri. Sumbangan mereka sangat besar terutama dalam menghidupkan kejayaan masa lalu. Masa lalu menjadi aspek penting dalam kehidupan manusia karena masa lalu adalah sumber inspirasi yang berfungsi sebagai pijakan menuju masa depan. Andil perpustakaan dalam upaya menghidupkan kembali kebesaran masa lalu tampak jelas dalam pengungkapan kembali khasanah kesusastraan purba pra-Kristiani yang menggunakan bahasa Latin kuno oleh kaum humanis.

\section{Tradisi Baru Perpustakaan di bawah PTKIN}

Warisan budaya adalah cerita sejarah tentang artifak, arsitektur, teks dan sesuatu yang tak tersentuh seperti bahasa, folklore (sastra) yang 
merupakan bagian dari sebuah kebudayaan. ${ }^{7}$ Perpustakaan adalah insitusi yang bertugas mengelola itu dalam bentuk koleksi ilmiah seperti buku, jurnal, majalah dan dokumen lainnya yang dikelola dan disajikan untuk kepentingan pemustakanya.

Perpustakaan menyediakan akses ke koleksi selaras dengan bidang penelitian, fokus kurikuler, atau kekuatan institusional. Perpustakaan juga menyediakan koleksi yang menggabungkan sumber dalam berbagai format, dapat diakses pemakai secara virtual maupun fisik. Perpustakaan pun membangun dan menjamin akses ke bahan yang unik, termasuk koleksi digital. Lain daripada itu Perpustakaan juga memiliki infrastruktur untuk mengumpulkan, mengatur, memberikan akses, menyebarkan, dan melestarikan koleksi yang dibutuhkan oleh pengguna, ${ }^{8}$ termasuk koleksikoleksi kebudayaan.

Koleksi kebudayaan ini memiliki arti yang penting karena, Pertama, sebagai informasi yang bisa menunjukkan unsur-unsur yang telah membentuk kebudayaan suatu bangsa atau kelompok. Kedua, sebagai sumber ilmu pengetahuan. Kebudayaan adalah hasil dari aktivitas cipta, karsa dan rasa manusia, sehingga muncul teknik atau pengetahuan dari aktivitas tersebut yang bisa dimanfaatkan dan diperbarui.

${ }^{7}$ Janet Stevenson, Dictionary of Information and Library Management. (London: A. \& C. Black, 2006), 49, http://www.credoreference.com/book/acbinfomanage.2006

${ }^{8}$ Budi Handarini, "Kontribusi Perpustakaan Terhadap Upaya Peningkatan Kualitas Perguruan Tinggi," LIBRARIA: Jurnal Perpustakaan 4, no. 1 (2016): 147.and higher education is a sub-system of the National Education System. Together with other sub-systems, colleges are required to seek the realization of the vision and mission of the National Education System as well as to optimize the implementation of the national strategy of national education development. One mission that must be realized is to seek expansion and equal access to quality education for all Indonesian people. Thus the realization of high-quality education is obligatory. College as an entity consisting of various sub-systems, among which is the library. That's why the success of universities to improve and maintain its quality, among others, are also determined by how much the contributions made by the sub-system, including libraries. The amount of contributions to improve the quality of colleges is directly proportional to the quality of the library. The realization of library management quality is affected by the condition of the elements of the existing library, such as infrastructure, funding, library collections, quality of service

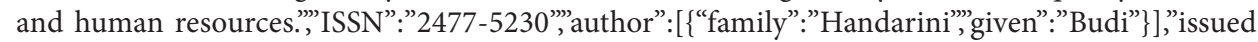
":\{“date-parts":[[“2016”]]\}\},"locator":"147”\}],"schema":"https://github.com/citation-style-language/ schema/raw/master/csl-citation.json”\} 
Ketiga, sebagai sumber kearifan atau nilai moral. Kebudayaan memuat ajaran tentang bagaimana hubungan dengan orang lain itu dilakukan, bagaimana memaknai kelahiran, perkawinan, kematian atau bagaimana menjalin hubungan dengan alam. Keempat, bernilai pariwisata ataupun ekonomi. Wujud kebudayaan muncul dalam bentuk-bentuk yang memiliki unsur estetika atau keunikan sehingga dapat dipertontonkan. Kebudayaan ditampilkan dan dikemas menarik sehingga dapat ditonton, dinikmati dan mendatangkan keuntungan. Di samping, itu bisa juga berfungsi untuk memperkenalkan suatu bentuk kebudayaan/negara tertentu. ${ }^{9}$

Jika konteksnya pelestarian budaya ini adalah pelestarian pengetahuan, maka Perpustakaan PTKIN Indonesia memili 2 (dua) tradisi baru yang kini sedang dikembangkan, yaitu:

1. Online Resource Skill, yaitu kemampuan yang dikembangkan perpustakaan dalam menelusur dokumen-dokumen atau informasi yang dikelola secara online. Dalam konteks budaya, informasi ini bisa berupa dokumen-dokumen atau naskah-naskah yang sudah dialihbentukkan dalam dokumen digital.

2. Writing skill, yaitu kemampuan yang dikembangkan perpustakaan untuk menulis dan menciptakan infomrasi baru dalam bentuk karya tulis. Menulis ini sebagai media menyampaikan ide-ide dan pengetahuan penulis kepada masyarakat umum. Disin persn pernulisan sebagai pelestari budaya akan bermakna sebagai pendokumentasian dan atau perekaman atau pengabadian budaya masyarakat. misalnya jika disuatu wilayah terdapat cerita rakyat atau legenda, maka cerita itu bisa direkam dalam cerita tertulis yang akan bisa dibaca tidak saja orang sekarang, tetapi akan bisa dikonsumsi oleh generasi yang akan datang.

Kedua aktifitas baru ini dapat dikatakan menjadi tradisi baru perpustakaan dalam melestarikan budaya di masyarakat. Karenanya, berdasarkan tugas yang diamanatkan kepada pustakawan, maka pustakawan

${ }^{9}$ Farid Rahmat Saleh, "PERPUSTAKAAN SEBAGAI PUSAT KEBUDAYAAN," UIN Yogyakarta, 2009, 2, http://digilib.uin-suka.ac.id/4124/1/BAB\%20I,V,\%20DAFTAR\%20PUSTAKA.pdf. 
memiliki peran dalam pelestarian budaya bangsa sehingga dapat membantu dalam meningkatkan budaya yang ada menjadi kebudayaan Indonesia. Kebudayaan Indonesia menurut Pamplet Kominfo adalah keragaman budaya daerah di Indonesia meliputi seni budaya, seni tari, seni suara, rumah adat, pakaian adat, upacara adat daerah, keindahan alam, aneka satwa, dan sumber daya alam yang potensial serta wilayah yang strategis. Apabila unsur-unsur budaya tersebut disusun dalam bentuk buku, maka pustakawan memiliki kewajiban untuk menyampaikan kepada pengunjung dan mempromosikannya agar setiap orang mengetahui budaya daerah, nasional, dan bahkan internasional.

\section{Penutup}

Sebagai penutup dapat disimpulkan disini bahwa perpustakaan tidak sekedar tempat buku yang dipajang saja, melainkan ada nilai-nilai penting lain yang terkandung di dalamnya. Paradigma perpustakaan sudah bergeser dari books oriented sudah ke arah user oriented, dari sekedar penataan buku di rak menjadi pusat sumber daya informasi. Budaya baru yang ditimbulkan dari kegiatan perpustakaan dalam konteks pelestarian budaya adalah pertama:Online Resource Skill, dan yang kedua adalah Writing Skill, dimana budaya baru itu berperan sebagai penyimpan dan menyajikan informasi baik yang tercetak maupun noncetak.

\section{Daftar Pustaka}

Elisha R.T. Chiware. "Positioning the Technological University Library in Higher Education and Human Resources Development in Africa." Library Management 31, no. 6 (July 27, 2010): 391-403. doi:10.1108/01435121011066153.

Floridi, Luciano. Information: A Very Short Introduction. Oxford, 1995.

Gordon, Rachel Singer. The Accidental Library Manager. Medford, N.J: Information Today, 2004. 
Gorman, G.E, and Peter Clayton. Qualitative Research For The Information Proffessional: A Practical Handbook. 2nd ed. London: Facet Publishing, 2005.

Handarini, Budi. "Kontribusi Perpustakaan Terhadap Upaya Peningkatan Kualitas Perguruan Tinggi." LIBRARIA: Jurnal Perpustakaan 4, no. 1 (2016): 127-58.

Kurniasih, Nuning. "Kualifikasi Pustakawan Di Era Digital.” In Prosiding Semiloka Kepustakawanan Indonesia 2015, 439-50. Jakarta: FPPTI, 2015.

Noruzi, Alireza. “Application of Ranganathan's Laws to the Web.” Webology 1, no. 2 (2004). http://eprints.rclis.org/handle/10760/7252.

Saleh, Farid Rahmat. "PERPUSTAKAAN SEBAGAI PUSAT KEBUDAYAAN." UIN Yogyakarta, 2009. http://digilib.uin-suka.ac.id/4124/1/BAB\%20 I,V,\%20DAFTAR\%20PUSTAKA.pdf.

Stevenson, Janet. Dictionary of Information and Library Management. London: A. \& C. Black, 2006. http://www.credoreference.com/book/ acbinfomanage. 